\title{
Needs of patients living with advanced disease
}

\author{
By Margaret I. Fitch
}

\section{Abstract}

When a person has a life-threatening illness, many changes occur. These changes are more than just physical changes and include psychosocial, practical and spiritual consequences. If disease progresses, the impact of these changes intensifies. Nurses who are caring for patients with advancing disease must be able to provide appropriate interventions if they are to help individuals cope. This paper highlights information regarding the needs of patients with advanced disease and emphasizes approaches that could be taken by cancer nurses in their care of these patients. The material is drawn from over a decade of interviewing patients about their experiences with cancer, the literature about patient needs, and discussions with care providers. The over-arching perspective is one of seeing human beings as bio-psychosocial-spiritual entities. Holding this perspective has implications for assessment and interventions in caring for patients with advanced disease.

"When I think back, think about the whole time I have been ill, no part of my life is untouched. Not one part of it. Everything is different than it was." (man with prostate cancer, mid-seventies)

When a person has a life-threatening illness, many changes occur. These changes are more than physical ones due to the disease and its symptoms, or the treatment and its side effects. There are also social, psychological, and spiritual changes for both the person who has the disease and for family members. All will feel some degree of impact and resulting emotional turmoil. Furthermore, should the threat of dying from the disease become a reality, and death becomes imminent, emotions escalate and can become overwhelming (McLean, 1993). Nurses who care for these individuals must be able to provide appropriate interventions if they are to help individuals cope with what is happening to them and the resultant emotional turmoil.

This paper will highlight information regarding needs of patients living with advanced disease and emphasize key approaches that could be taken by nurses to ensure these patient needs are met. The material is drawn from over a decade of interviewing patients about their experiences with cancer, reading research reports about patient needs and perspectives, and talking with a wide range of care providers. I have selected some of my favorite quotes from patient interviews to illustrate key perspectives in each topic area. The over-arching perspective is one of seeing human beings as biopsychosocial-spiritual entities, more than just physical beings. Holding this perspective as a nurse has implications for how cancer nursing care is provided.

\section{Human needs}

As human beings, we all have physical, psychological, social, emotional, spiritual, informational, and practical needs (Ferrell, 1996). Each day, we work to fulfil these needs - we rest, sleep, eat, work, play, and develop patterns or ways of coping. However, when an illness strikes, we may not be able to meet our daily needs in the same way. New demands may appear and anxieties and uncertainties emerge (see Figure One). Suddenly, we may feel vulnerable, perceive that things are out of control, and believe we do not know what to do about the situation. We may have to access new information, learn new skills, or seek help from other people before our needs can be met.
Some individuals facing illness are able to mobilize their own resources and social networks and obtain the help they require when they have access to appropriate information, support and communication. These individuals find ways to meet the new demands of the situation; others do not. They continue to experience difficulties and emotional distress in an ongoing way and their needs remain unmet (Canadian Cancer Society, 2003). They require additional support and specialized interventions in order to cope with what is happening to them.

When caring for individuals who are ill, cancer nurses must be able to assess the type of difficulties individuals are experiencing, how much emotional distress those difficulties are creating, and identify whether or not the individuals have the resources available to cope with the situation. Based on a comprehensive assessment, interventions can be tailored to meet the person's particular constellation of needs.

\section{Physical needs}

What's most troublesome? Well, I'd say it's not one thing. It's all of the symptoms - the pain, the tiredness, the nausea, not sleeping - it's all of them. (ovarian cancer patient, mid-sixties)

As a patient becomes progressively ill, symptoms and treatment side effects become more numerous and more pronounced. Although the specific symptoms depend upon the particular type and stage of disease (see Table One), the most common symptoms include pain, loss of appetite, fatigue, weakness, weight loss, constipation, difficulty breathing, confusion, nausea, vomiting, cough, and dry or sore mouth (Fitch \& Steele, 2003; Ashbury, Findlay, Reynolds \& McKerralehen, 1998). However, patients do not often experience a single symptom. The most common experience for the patient is to have a cluster or constellation of symptoms with one influencing the others. For example, pain will be exacerbated if sleep is disturbed or fatigue is heightened. One of the challenges of clinical care is to understand how the patient

Margaret I. Fitch, RN, PhD is Director of the Psychosocial and Behavioural Research Unit at Toronto Sunnybrook Regional Cancer Centre. Contact e-mail:marg.fitch@sw.ca

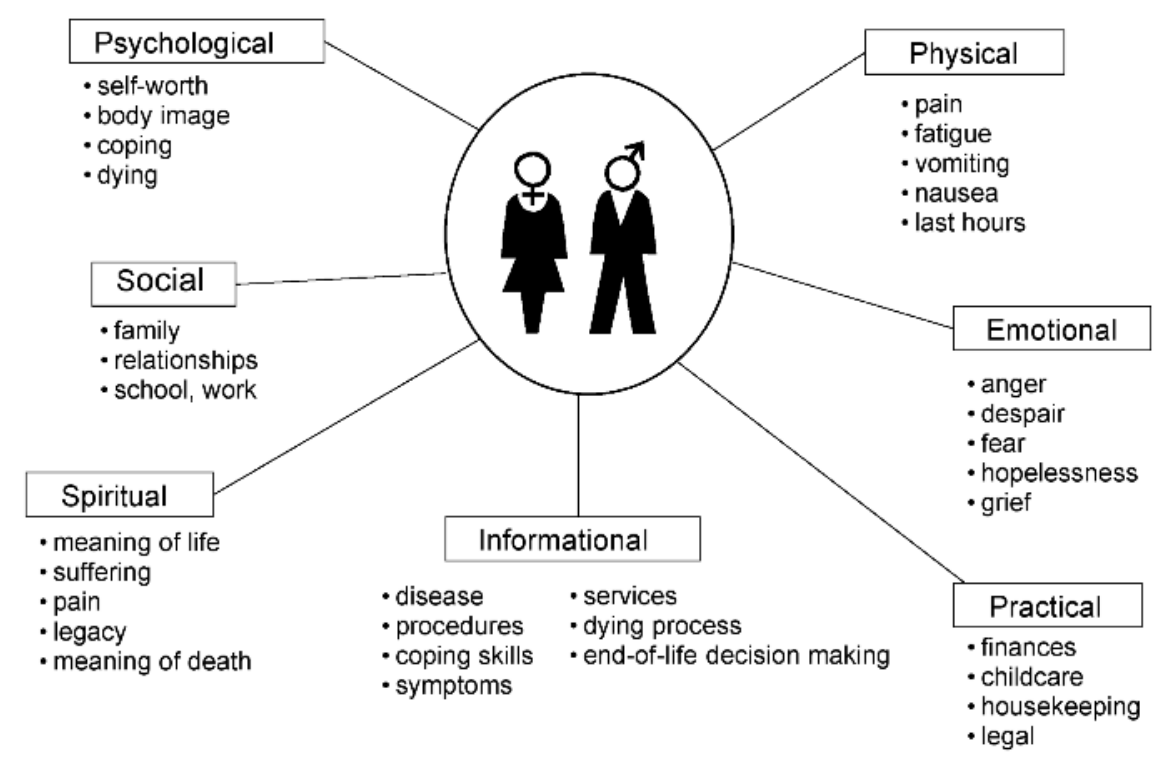

Figure One. Needs of patients with life-threatening illness (Fitch, 2000) 
experiences these symptom clusters and provide interventions aimed at the cluster, not at an individual symptom in isolation (Dodd et al., 2004).

Patients experience increased emotional distress if their symptoms are not attended to and will suffer decreased quality of life as a result (Singer, Martin \& Kelner, 1999). Evidence is emerging that elevated emotional distress as a result of poor symptom management is linked to decreased survival, particularly in patients with advanced disease (Edmonds, Karlsen, Khan, \& Addington-Hall, 2001). Therefore, one of the key goals in caring for individuals with advanced disease is to provide relief from pain and other distressing symptoms. Unfortunately, some patients report that they believe their symptoms were not adequately addressed (see Table Two).

Physicians and nurses may need to try a variety of approaches or interventions to find the most effective way of managing the side effects and symptoms (Preston \& Cunningham, 1998). Constant monitoring or assessment of the patient's physical comfort is important to determine if particular interventions are useful and to make appropriate changes when they are not. If the intervention is not working, rapid adjustment and implementation of new interventions is of paramount importance. Clinical teams have found the use of standardized symptom checklists for assessment and documentation together with predefined symptom protocols effective for rapid adjustment (Sarna, 1998).

\section{Table One. Physical symptoms reported by patients with advanced cancer*}

\begin{tabular}{|l|l|l|}
\hline & \multicolumn{2}{|l|}{$\begin{array}{l}\text { Proportion of Patients } \\
\text { Reporting Symptoms }\end{array}$} \\
\hline Physical Symptom & $\begin{array}{l}\text { Lung Cancer } \\
\text { Patients N=86 }\end{array}$ & $\begin{array}{l}\text { Palliative } \\
\text { Patients N=63 }\end{array}$ \\
\hline Lack of energy & 68.6 & 80.9 \\
\hline Shortness of breath & 48.8 & 57.1 \\
\hline Coughing & 46.5 & 31.7 \\
\hline Pain & 33.7 & 46.0 \\
\hline Decreased appetite & 30.2 & 20.6 \\
\hline Nausea/Vomiting & 15.1 & 9.5 \\
\hline * (Fitch \& Steele, 2003) \\
\hline
\end{tabular}

Table Two. Cancer patients who report they did not receive adequate help for symptoms

\begin{tabular}{|l|l|l|}
\hline Symptoms & $\begin{array}{l}\text { Ovarian Cancer } \\
\text { Patients with } \\
\text { Recurrent Disease } \\
\text { N=95* Proportion } \\
\text { reporting } \\
\text { inadequate help }\end{array}$ & $\begin{array}{l}\text { Prostate Cancer } \\
\text { Patients (mixed } \\
\text { stages) N=621** } \\
\text { Proportion } \\
\text { reporting } \\
\text { inadequate help }\end{array}$ \\
\hline Side effects & 23.0 & 22.0 \\
\hline Difficulty sleeping & 43.0 & Not reported \\
\hline $\begin{array}{l}\text { Difficulty with bowels } \\
\text { or incontinence }\end{array}$ & 65.0 & 35.0 \\
\hline Pain & 15.0 & 19.0 \\
\hline Sexual function & 60.0 & 53.0 \\
\hline * (Fitch, Gray, \& Franssen, 2000) \\
** (Fitch, Johnson, et al., 1999) \\
\hline
\end{tabular}

\section{Informational needs}

"You know, what made all the difference to me was being able to get information, get information I could understand. It was sort of like turning a light on in a room." (breast cancer survivor, mid-fifties)

Individuals who are becoming progressively ill want to understand what is happening to them and to their bodies and want to participate in the decisions about how they will spend their remaining days . However, to engage in the discussions and make informed decisions, access to relevant information is important.

Patients rate as highly important having access to information about bodily conditions, their disease, treatment options, and treatment side effects (Fitch, Gray \& Franssen, 2000; Fitch, 2004) (See Table Three). Many patients describe having an illness as entering an unfamiliar world filled with a great deal of new language. They find the hospital and clinic settings overwhelming and trying to understand the language of health care - the words health care professionals use every day - is a huge challenge. Patients often report difficulty accessing pertinent information about their disease and finding a health care professional who will help them apply the information to their own situation (Fitch, Nicoll, \& Keller-Olman, 2005). Recent reports have indicated that cancer patients are not satisfied with the information they received (see Table Four) and considered this one of the most problematic areas of care (Fitch \& Green, 2005).

When individuals do not have information, they can experience uncertainty, increased anxiety, or elevated frustration (Salminea, Vive, Poussa, \& Knifsund, 2004; Davidson, Degner, \& Morgan, 1995). Lack of pertinent information means they are unable to engage in the decision-making process as an informed participant. If an individual knows what to expect, $\mathrm{s} / \mathrm{he}$ is in a better position to prepare for the future eventuality or to make choices about available options that are in concert with personal values and goals.

As the time of death draws nearer, many patients and family members have questions about the dying process and about death itself. Some will have heard about others' experiences and wonder if theirs will be the same. Patients and family members may feel better prepared if they can talk about anticipated bodily changes and what they might expect to feel and see.

\section{Practical needs}

"Once we took Dad home, it was wonderful for him. I could tell. But it meant there were so many things we had to do. I mean, if we all went out, we had to get a sitter. You couldn't leave him alone in the house." (daughter in her mid-forties of a man with GI cancer)

Many practical considerations emerge during an illness episode (Canadian Cancer Society, 2003; Sanson-Fisher, Girgis, Boyes, Bonevski, Burton, \& Cook, 2000; Ashbury, et al., 1998). These may include considerations regarding work, school, finances, childcare or elder care, or household responsibilities. Illness often implies people are not able to meet their usual obligations or fulfil their normal responsibilities. Alternative arrangements must be made and may require transferring major responsibilities to others. As individuals become more incapacitated, many details concerning care may need to be organized.

When an illness progresses and death is inevitable, several key practical issues emerge. One important practical decision that some individuals will need to make is where he or she will die: at home or in an institution. To have people remain at home as long as possible and to die in that setting, if they wish, requires substantial planning and access to a good home support service. Where to die is a decision that must be thought about carefully by both the patient and the care providers. Both settings have benefits and drawbacks. For example, in a hospital setting there is 24-hour care by nursing staff, while at home nurses may only visit once or twice a day and the family carries the major burden of the caregiving; in hospital, 
the person may feel more separated from the family, while at home she or he can be part of the household (Edmonds et al., 2001; Grande et al., 1997).

Two other practical issues that may emerge as illness progresses include making a will/estate planning and making funeral arrangements. Writing a will provides a vehicle for a person to plan, with certainty, how his or her possessions will be dispersed following death. It will also help to offset worries the person may have about how the family will manage after the death. Making arrangements regarding the funeral before death can enable the person to be involved in decisions about what will happen to his or her body and the funeral ceremony itself.

\section{Psychological needs}

"I found it hard to realize I did not have control. I thought I did, before this illness. I made decisions. I planned what I'd do. I made lists. Now it is all different." (ovarian cancer patient, 48)

Throughout the course of an illness, there can be various psychological impacts (Ridner, 2004; Farrell \& Lewis, 2000; Vachon, 1998). Illness often brings forth a sense of personal vulnerability and loss of control over one's life. Patients will report they feel that events happen around them and they are being carried along through none of their own efforts. Some liken the feeling to that of being on a roller coaster with its sudden ups, downs, and turns at a rapid pace. Individuals find their body is not functioning as it used to, and they cannot do the things they want to do. Not only is their body image undergoing change, but their sense of self, who they are, and their self-esteem may be altered. When a person is not able to meet his or her own expectations, is not able to accomplish the goals that are important, or is not able to maintain significant relationships, psychological distress may emerge (see Table Five).

Psychological distress may be exhibited as anxiety or depression and may be experienced to varying degrees. To some extent, all individuals who are dying will exhibit anxiety. However, the anxiety may range from mild to moderate to severe forms (Zabora, Brintzenhofeszoc, Curbow, Hooker, \& Piantadosi, 2001). Having someone in whom to confide and talk about what is happening is important for all, but those with moderate to severe forms will benefit from referral to a mental health professional (e.g., social worker, psychologist) (National Comprehensive Cancer Network, 2002). Only about 25\% will experience clinical depression although others may feel disheartened or a sense

Table Three. Proportion of cancer patients who ranked information as important

\begin{tabular}{|l|l|l|}
\hline & \multicolumn{2}{|l|}{ Proportion of Patients } \\
\hline $\begin{array}{l}\text { Type of } \\
\text { Information }\end{array}$ & $\begin{array}{l}\text { Ovarian Cancer } \\
\text { Patients N=315* }\end{array}$ & $\begin{array}{l}\text { Prostate Cancer } \\
\text { Patients N=621** }\end{array}$ \\
\hline Medical condition & 88 & 80 \\
\hline $\begin{array}{l}\text { Physical effects } \\
\text { of cancer }\end{array}$ & 83 & 72 \\
\hline Treatment choices & 81 & 72 \\
\hline $\begin{array}{l}\text { Side effects of treatment } \\
\text { How to relieve } \\
\text { physical discomfort }\end{array}$ & 79 & 57 \\
\hline Emotional reactions & 64 & 45 \\
\hline $\begin{array}{l}\text { Where to get supplies } \\
\text { and equipment }\end{array}$ & 48 & 45 \\
\hline $\begin{array}{l}\text { Counselling } \\
\text { services available }\end{array}$ & 48 & 30 \\
\hline $\begin{array}{l}* \text { (Fitch, Gray, DePetrillo, Franssen \& Howell, 1999) } \\
* * \text { (Fitch, Johnson, et al., } 1999)\end{array}$ \\
\hline
\end{tabular}

of helplessness at times. Those at greatest risk for depression include patients with advanced disease, a history of a psychological disorder or alcoholism, increased physical impairment, unmanaged pain, concurrent illnesses that produce depressive symptoms, certain medications, and lack of social supports (Massie, Gagnon \& Holland, 1994).

\section{Spiritual needs}

"I used to think nothing could touch me. Nothing would hit me. But this illness, it changed that. I'm not invincible." (breast cancer patient, 58)

Life-threatening illness challenges one's spirituality. A lifethreatening diagnosis often evokes questions - Why me? Why now? Why this way? It threatens hope and motivates a search to find

\begin{tabular}{|l|l|l|}
\hline \multicolumn{2}{|l|}{$\begin{array}{l}\text { Table Four. Proportion of cancer patients } \\
\text { who were dissatisfied with information received }\end{array}$} \\
\hline & \multicolumn{2}{|c|}{ Proportion of Patients } \\
\hline Type of Information & $\begin{array}{l}\text { Ovarian Cancer } \\
\text { Patients with } \\
\text { recurrent } \\
\text { disease N=95* }\end{array}$ & $\begin{array}{l}\text { Prostate Cancer } \\
\text { Patients with } \\
\text { recurrent } \\
\text { disease N=120** }\end{array}$ \\
\hline Medical condition & 15 & 25 \\
\hline Physical effects of cancer & 18 & 31 \\
\hline Treatment choices & 17 & 19 \\
\hline Side effects of treatment & 10 & 21 \\
\hline $\begin{array}{l}\text { How to relieve } \\
\text { physical discomfort }\end{array}$ & 12 & 24 \\
\hline Emotional reactions & 44 & 24 \\
\hline $\begin{array}{l}\text { Where to get supplies } \\
\text { and equipment }\end{array}$ & 12 & 19 \\
\hline $\begin{array}{l}\text { Counselling } \\
\text { services available }\end{array}$ & 20 & 20 \\
\hline$*$ (Fitch, Gray, DePetrillo, Franssen \& Howell, 1999$)$ \\
$* *$ Fitch, Johnson, et al., 1999$)$
\end{tabular}

Table Five.

Frequently identified psychosocial issues by cancer patients

\begin{tabular}{|l|l|c|}
\hline & \multicolumn{2}{|l|}{ Proportion of Patients Reporting Issue* } \\
\hline Issue & $\begin{array}{l}\text { Lung Cancer } \\
\text { Patients N=86 }\end{array}$ & $\begin{array}{l}\text { Palliative Care } \\
\text { Patients N=63 }\end{array}$ \\
\hline $\begin{array}{l}\text { Fears about } \\
\text { cancer spreading }\end{array}$ & 58 & 36 \\
\hline $\begin{array}{l}\text { Fears of } \\
\text { cancer returning }\end{array}$ & 49 & 20 \\
\hline Fears about pain & 41 & 37 \\
\hline $\begin{array}{l}\text { Fears of physical } \\
\text { disability/deterioration }\end{array}$ & 34 & 42 \\
\hline Feeling down/depressed & 40 & 39 \\
\hline Feeling anxious & 33 & 25 \\
\hline $\begin{array}{l}\text { Confusion about why } \\
\text { this has happened to me }\end{array}$ & 19 & \\
\hline$*$ (Fitch \& Steele, 2003) & & \\
\hline
\end{tabular}


meaning or make sense of the situation. It intensifies yearning to love and belong; threatens core beliefs about the world, how it works and one's place in it; and stimulates one to look beyond. "Spirituality" refers to the dimension that motivates meaning - making and selftranscendence of connectedness with one's self and with others, including an ultimate other (Taylor, 1998). It is the dimension that prompts us to make sense of the universe, as we know it and to relate harmoniously with nature, self, and others. In contrast, religiosity is viewed in a somewhat narrower fashion as a representation and expression of spirituality with a specific view of the world.

As patients struggle with issues of spirituality, these issues are often mislabeled as psychosocial or emotional issues (i.e., fear, anxiety, sadness, guilt, despair, hopelessness, mention of faith, restlessness). Spiritual issues may become evident as patients voice questions such as, "Why is this happening to me?" They may also express these needs in terms of feeling guilty for having fallen away from their faith community or from faith practices.

A significant issue for those who are facing death is to find ways of maintaining hope and finding meaning (Schlesselman, 1998). Even though there may no longer be a realistic hope for cure of the disease, there can be hope in wishes for achieving short-term goals (e.g., a night without pain, a good night's sleep, an easy death, the resolution of a conflict). Reframing hope to focus on the present and on specifics, rather than vague uncertainties, can be useful (Schlesselman, 1998). Hope is a natural part of the human existence and has been cited as nourishing individuals in difficult times and serving as a buffer to stress (Post-White, Ceronsky, Kreitzer, Nickelson, Drew, MacKay, et al., 1996). It is defined as a dynamic inner power that enables transcendence of a present situation and fosters a positive new awareness of being; it is also seen as a realitybased belief that a positive future exists, but where the ever-present possibility of dying is acknowledged.

Advancing disease often leads people to question what their lives have really meant and to sort through whether they are leaving a legacy. They wonder about what will happen to their families, their lifework, and their life goals. As individuals review their lives, they may gain insight about themselves and an understanding about some of the relationships and events that have occurred (Holloway \&

\section{Table Six. Proportion of cancer patients who reported fear of death/dying}

\begin{tabular}{|c|c|}
\hline Patient Group & $\begin{array}{l}\text { Proportion Reporting } \\
\text { Fear of Death/Dying }\end{array}$ \\
\hline $\begin{array}{l}\text { Ovarian cancer patients* } \\
\text { recurrent disease }(n=93) \\
\text { no recurrent disease }(n=170) \\
\text { Gynecological cancer patients }(n=103)^{* *}\end{array}$ & $\begin{array}{l}84 \% \\
33 \% \\
66 \%\end{array}$ \\
\hline $\begin{array}{l}\text { Prostate cancer patients } * * * \\
\text { recurrent disease }(n=120) \\
\text { no recurrent disease }(n=845)\end{array}$ & $\begin{array}{l}18 \% \\
13 \%\end{array}$ \\
\hline $\begin{array}{l}\text { Patients receiving } \\
\text { palliative radiation } * * * *(n=63)\end{array}$ & $38 \%$ \\
\hline $\begin{array}{l}\text { Lung cancer patients } \\
\text { mixed stages } * * * *(n=86)\end{array}$ & $37 \%$ \\
\hline $\begin{array}{l}\text { Cancer patients mixed stages/ } \\
\text { all sites } * * * * *(n=457)\end{array}$ & $53 \%$ \\
\hline \multicolumn{2}{|c|}{$\begin{array}{l}*(\text { Fitch, Gray, \& Franssen, 2000) } \\
\text { ** (Fitch, Steele, Alderson, Barrow, \& Constantine, 2004) } \\
\text { *** (Fitch, Johnson, et al., 1999) } \\
\text { **** (Fitch \& Steele, 2003) } \\
* * * * * \text { (Fitch, Vachon, Greenberg, \& Franssen, 1996) }\end{array}$} \\
\hline
\end{tabular}

Wheeler, 1996). It can be a time of inner growth and achieving a profound sense of peace. It may also be a time when individuals feel a strong motivation to resolve unfinished business or issues. Patients may require help to accomplish these last important goals.

\section{Social needs}

"When you are ill, you really find out who your friends are, and who will help. I have been both surprised and disappointed by what has happened; surprised at who has helped and who cannot even talk about it." (breast cancer survivor, 52)

Social support is a key factor in an individual's ability to cope with a stressful situation. It has to do with the nature of interactions or exchange in social relationships and how an individual evaluates those interactions as supportive (Stewart, 1993; Sherbourne \& Stewart, 1991). Generally, social support is conceived as having four attributes: instrumental (tangible goods and services), emotional (caring, empathy, love, trust), informational (facts, problem-solving, feedback about performance), and appraisal (affirmation, endorsement). One or more of these attributes can be at risk during illness (Burns, Craft, \& Roder, 2005). For example, if work has provided a primary route to social support, and suddenly the person is not able to go to work, this route may be lost. Not being able to engage in normal social activities could mean a reduction in the amount of support a person feels.

Social support comes from interactions with family members, friends, peers, and health care providers. A person who perceives s/he has good social support is likely to experience less anxiety and depression and to see a situation more positively. Those who have a confidant, or even believe they have someone in whom they can confide, report less emotional distress (Maunsell, Brisson, \& Deschenes, 1995). For health care professionals, it is important to recognize that having a relationship does not always mean a person is supported or feels supported in it. Some relationships are stressful and demanding. There is wide variation in the quality of support that exists in the same types of relationships (i.e., marriage, parent-child, etc.). As well, it is not so much the number of relationships that are important to providing support, but the quality of the existing relationships.

Issues and challenges can emerge as the patient becomes sicker, relationships change, and family and friends experience grief regarding the impending losses. Both the patient and the family members may begin a grieving process before the person has died called anticipatory grief (Loney, 1998). Many of the hallmarks of bereavement can actually be observed as the person mourns in advance of death for the impending loss. Family members are preparing in many ways for a life without the person who is dying. There is a sense the world is changing irrevocably and it will never be the same again. Imagining the world without a loved one can evoke feelings of overwhelming despair, helplessness, and profound loss in a family member and may prevent the individual from providing support to the person who is dying.

\section{Emotional needs}

"I have good days and not so good days. I feel happy about some things and sad about others. I wish I could change things and not have this illness, but I can't." (woman with multiple myeloma, 56)

To be faced with one's own death evokes various emotions (Canadian Association of Psychosocial Oncology, 2003). Each person will react in his or her own way. There may be shock and disbelief that this could be happening, anger that it is happening at this time in one's life, or acceptance that one's appointed time has arrived. A range of worries usually emerge as a person begins to imagine the ending of his or her life and what will happen to the people s/he loves. As bodily changes occur and the person must depend increasingly on others for assistance, concerns about being a burden and not contributing to the family may arise. Frustration may emerge when a person is not able to do something that s/he would do normally. Regrets about things one did as well as things left undone can create a feeling of guilt and remorse. 
Fears may also abound as disease advances. Patients may fear the unknown future or fear death itself (see Table Six). They may worry about dying with pain and discomfort or dying alone). Some fear abandonment by family, friends, or even health care professionals. Others fear losing control over their bodies, their minds, their ability to make decisions, their lives, and how they will spend their final days.

For some individuals, the emotions may be so overwhelming and frightening, the best way of coping is to push them aside and carry on as if nothing is wrong. When this happens, individuals can be labelled as "in denial." However, using denial at times can be a very useful coping strategy (Gorman, 1998). Using denial can help to keep emotions contained when they threaten to overwhelm a person. Denial can also be useful as a coping strategy when nothing can be done to change the outcome of a situation. When a person finds this is the case, it is sometimes easier to avoid dwelling on the future undesirable outcome and to focus one's energy on the present and what can be accomplished. It is important to recognize there is no "right way" to cope with this type of situation and no "appropriate" time schedules for feelings.

For individuals living with advanced disease and approaching death, each day requires balancing - balancing living and dying - and confronting uncertainty. For so many, it is a time of intense emotions. Patients' stories of this time are filled with courage, despair, hope, and turmoil. The following quotations from individuals facing death illustrate these points:

"This disease has completely eroded almost all future dreams and hopes of mine. Due to the lack of adequate treatment of this disease, my life expectancy is extremely short. I will not see my children mature into adulthood. I will not share the years ahead with my husband. I am not able to do physically taxing activities with my friends and family. This is particularly difficult because my children are still young. I am not able to work any more - which changes our financial picture somewhat. But the most significant aspect of this, for me, is knowing that my children won't have a mother for much longer."(ovarian cancer patient, 32)

"I look at life in a more positive way and appreciate things and life more. Our spiritual life has grown. I take time to smell the roses. The small things that seemed so important are no longer so... the dishes can sit in the sink while I go for a walk... my life is not so rushed to get everything done." (woman with colorectal cancer, 68)

"I cannot go outside as much. But I am not left alone very much. I really feel trapped and have no life at all now... I cannot do a lot of things I want to do. I can no longer afford to do some of things I wanted to do that would have made my life easier. People avoid me."(woman with lung cancer, 42)

"My life is totally different now. I need a long rest each afternoon so there are very few hours each day for getting the basic activities done. However, I treasure the time friends visit or I talk on the phone with them. When my husband takes me for a drive there is a heightened appreciation for all the countryside I see around me. I still consider myself to have a good quality of life despite my losses." (ovarian cancer patient, 71)

\section{Intervention approaches}

Nurses caring for cancer patients with advanced disease must first of all recognize that no two individuals will experience any given situation exactly the same way and no two individuals will react and respond in the same way (Lazarus \& Folkman, 1984). Individuals react and, subsequently, respond in accordance with their perception of the situation in which they find themselves. Their interpretation of the event/situation's inherent harm or threat for them, and those who are important to them, will determine their subsequent emotional, cognitive, and behavioural approaches to coping with their situation. Nurses must conduct a thorough assessment using both closed and open-ended questions in order to understand the unique perspective of each patient (Nicholas \& Veach, 2000). It may take some time to build a trusting relationship so that person will feel comfortable talking about sensitive and difficult topics and the nurse will need to be non- judgmental and seek to understand situations and events from the patient's viewpoint. The nurse must try to understand the threats, losses, and challenges the person perceives. A major challenge most nurses face is to resist judging both the perspective and the coping strategies a patient is using in a particular situation when they are not the same as those the nurse would use. It is critically important for the nurses to be able to set aside his or her own personal views and ideas about how to cope with a situation and not confuse them with approaches the patient is using. What may be effective and helpful for one person may not be helpful for another.

During conversations with a patient, nurses need to identify the goals and values that are important to the individual. Understanding what is important to the individual provides a frame of reference for planning what ought to be done, identifying the salient outcomes for interventions, and determining the criteria to evaluate success. The patient's desires or wishes must become the overriding consideration. Tension can emerge if the nurse does not have the same outcomes in mind as the patient does. For example, the nurse might think everyone in the family ought to be told about an impending death, but the patient might not want to have everyone informed; or a patient may wish to stop all nutritional intake while the health care professional wishes to keep intravenous fluids running; or a patient does not want to take a full dose of pain medication so he will be alert, while the health care professional thinks the full dose is needed to control the pain.

There are two primary goals for intervening with patients who are living with advanced disease: 1) lessen the impact of symptoms and side effects, and 2) assist the individual to cope with the impact of the situation (Fitch, 2003). To achieve these goals, interventions need to be tailored to the individual. To know the best way to tailor interventions for a person, a conversation must begin about that person's wishes and appraisal of the situation (Lazarus \& Folkman, 1984). The conversation should focus on issues such as how involved the individual wishes to be in decision-making about his or her care and what information is needed in order to participate in the desired manner. The individual needs to be given ample and open opportunity to voice any concerns or ask questions without fear of being judged or having the expressed concerns dismissed. These interactions with the patient and family members should be held on an ongoing basis. Situations change over time and people change their ideas. Without regular conversations, the health care team may not be providing truly patient-centred care.

The myriad of issues that could arise for the person who is dying and for family members emphasizes the need to work with an interdisciplinary team. Although one member of the team may have primary contact with the patient - perhaps the physician or the nurse - having easy access to other disciplines can be organized. Based on the nature of the issue the patient is experiencing, the patient may need to be seen by a member of another discipline or that professional may need to be consulted by the patient's doctor or nurse for advice.

Some authors have recommended the use of standardized symptom checklists (Sarna, 1998) or psychosocial screening instruments (Zabora et al., 2001). These tools allow for easy, routine assessment and documentation of both physical and psychological symptoms. Ongoing monitoring of the effectiveness of interventions can also be easily tracked with application of these tools and referral to other disciplines can be made in a timely fashion.

\section{Summary}

Confronting one's own death or the death of a family member is not easy. Most people in this situation experience a myriad of emotions. While some manage remarkably well, others need specialized assistance. To provide effective care, it is very important to tailor the interventions to the patient's unique perspectives and goals. Building a trusting relationship with the individual patient is key to gaining a better understanding of a patient's goals and values. When nurses care for individuals with advanced disease, it is imperative that patients' goals and values are central to the care planning process. 
Ashbury, F.D., Findlay, H., Reynolds, B., \& McKerralehen, K.A. (1998). Canadian survey of cancer patients' experiences: Are their needs being met? Journal of Pain and Symptom Management, 6(5), 298-306.

Burns, C.M., Crafts, P.S., \& Roder, D.M. (2005). Does emotional support influence survival? Findings from a longitudinal study of patients with advanced cancer. Supportive Cancer Care, 13, 295-302.

Canadian Association of Psychosocial Oncology. (2003). The emotional facts of life with cancer. Calgary: Author.

Canadian Cancer Society (2003). Breaking down the barriers: A study of cancer patients and caregiver needs in Ontario. Toronto: Author.

Davidson, B.J., Degner, L.F., \& Morgan, T.R. (1995). Information and decision-making preferences of men with prostate cancer. Oncology Nursing Forum, 22(9), 1401-8.

Dodd, M.J., Miaskowski, C., \& Lee, K.A. (2004). Occurrence of symptom clusters. Journal of the National Cancer Institute Monogram, 32, 76-78.

Edmonds, P., Karlsen, S., Khan, S., \& Addington-Hall, J. (2001). A comparison of the palliative care needs of patients dying from chronic respiratory diseases and lung cancer. Palliative Medicine, 15(4), 287-95.

Farrell, C., \& Lewis, J. (2000). The Cancer Experience. London: National Centre for Social Research.

Ferrell, B.R., (1996). The quality of lives: 1525 voices of cancer. Oncology Nursing Forum, 23, 909-916.

Fitch, M.I. (2004). Patient perspectives regarding information: Development of a performance indicator tool. Supportive Care in Cancer, 12(6), 410.

Fitch, M.I. (2003). Psychosocial management of patients with recurrent ovarian disease: Treating the whole person to improve quality of life. Seminars in Oncology Nursing, 19(3), 40-53.

Fitch, M.I., (2000). Supportive Care for Cancer Patients. Hospital Quarterly, 3, 39-46.

Fitch, M.I., Gray, R.E., \& Franssen, E. (2000). Women's perspectives regarding the impact of ovarian cancer. Cancer Nursing, 23(5), 359-366.

Fitch, M.I., Gray, R.E., DePetrillo, D., Franssen, E., \& Howell, D. (1999). Canadian women's perspectives on ovarian cancer. Cancer Prevention \& Control, 3(1), 52-60.

Fitch, M.I., Johnson, B., Gray, R.E., \& Franssen, E. (1999). Survivors' perspectives on the impact of prostate cancer: Implications for oncology nurses. Canadian Oncology Nursing Journal, 9(1), 23-8.

Fitch, M.I., Nicoll, I., \& Keller-Olaman, S. (2005). Breast cancer information dissemination: Finding out what works. Supportive Care in Cancer, 13(6), 469.

Fitch, M.I., Steele, R., Alderson, D., Barrow, K., Constantine, T., \& Doyle, C. (2004). Understanding supportive care needs of patients with gynecological cancer. Supportive Care Cancer, 12(6), 411.

Fitch, M.I., \& Steele, R. (2003). Supportive care needs of cancer patients: Looking beyond the obvious. Supportive Care Cancer, 11(6), 423.

Fitch, M.I., Vachon, M., Greenberg, M., \& Franssen, E. (1996). Needs of cancer patients and their family members attending a comprehensive cancer centre. Proceedings of the 9th International Nurses in Cancer Care Conference; Aug 12-15, Brighton, U.K. p. 68.

Gorman, L.M. (1998). Denial. In, R.M. Carroll-Johnson, L.M. Gorman, \& W.J. Bush (Eds.), Psychosocial Nursing Care (pp. 171-181). Pittsburgh, PA: Oncology Nursing Press, Inc.

Grande, G.E., Rodd, C.J., \& Barcley, S.I. (1997). Supports needed in the last year of life: Patients and carer dilemmas. Palliative Medicine, 11(3), 202-8.
Gray, R.E., Greenberg, M., Fitch, M.I., Sawka, C., Hampson, A., Lebrecque, M., \& Moore, B. (1998). Information needs of women with metastatic breast cancer. Cancer Prevention \& Control, 2(2), 57-62.

Herth, K. (1993). Hope in the family caregiver of terminally ill people. Journal of Advanced Nursing, 18, 538-48.

Holloway, I., \& Wheeler, S. (1996). Qualitative Research for Nurses. Edinburgh: Blackwell Science.

Lazarus, R.S., \& Folkman, S. (1984). Stress, appraisal and coping. New York: Springer.

Loney, M. (1998). Death, dying and grief in the face of cancer. In E.S. Burke (Ed.), Psychosocial dimensions of oncology nursing care (pp. 151-179). Pittsburgh, PA: Oncology Nursing Press, Inc.

Massie, M.J., Gagnon, P., \& Holland, J.C. (1994). Depression and suicide in patients with cancer. Journal of Pain and Symptom Management, 9, 325-340.

Maunsell, E., Brisson, J., \& Deschenes, L. (1995). Social support and survival among women with breast cancer. Cancer, 76, 631-637.

McLean, G.L. (1993). Facing death: Conversations with cancer patients. London: Churchill Livingstone.

National Comprehensive Cancer Network. (2002). NCCN Practice Guidelines in Oncology: Distress management. Retrieved July 3, 2002, from http://www.nccn.org/ physician_gls/index.html.

Nicholas, D.R., \& Veach, T.A. (2000). The psychosocial assessment of the adult cancer patient. Professional Psychology Research Practice, 206-15.

Post-White, J., Ceronsky, C., Kreitzer, M.J., Nickelson, K., Drew, D. MacKay, K.W., et al. (1996). Hope, spirituality, sense of coherence and quality of life with cancer. Oncology Nursing Forum, 23, 1303-1309.

Preston, F.A., \& Cunningham, R.S. (1998). Clinical Guidelines for Symptom Management in Oncology. New York: Clinical Insights Press Inc.

Ridner, S.H. (2004). Psychological distress: Concept analysis. Journal of Advanced Nursing, 45(5), 536-45.

Salminea, E., Vive, J., Poussa, T., \& Knifsund, S. (2004). Unmet needs for information flow between breast cancer patients, their spouses and physicians. Supportive Care Cancer, 12, 663-668.

Sanson-Fisher, R., Girgis, A., Boyes, A., Bonevski, B., Burton, L., \& Cook, P. (2000). The unmet needs of patients with cancer. Cancer, 88(1), 217-25.

Sarna, L. (1998). Effectiveness of structure of nursing assessment of symptom distress in advanced lung cancer. Oncology Nursing Forum, 25(6), 1041-7.

Schlesselman, S.M. (1998). The influence of hope on the psychosocial experience. In, R.M. Carroll-Johnson, L.M. Gorman, \& W.J. Bush (Eds.), Psychosocial Nursing Care (pp 83-89). Pittsburgh, PA: Oncology Nursing Press, Inc.

Sherbourne, C., \& Stewart, A. (1991). The MOS social support survey. Social Science and Medicine, 32(6), 705-714.

Singer, P.A., Martin, D.K., \& Kelner, M. (1999). Quality end of life care: Patients' perspectives. Journal of the American Medical Association, 281(2), 163-8.

Stewart, M. (1993). Integrating social support in nursing. Newbury Park, CA: Sage Publications.

Taylor, E.J. (1998). Spirituality and the cancer experience. In R.M. Carroll-Johnson, L.M. Gorman, \& W.J. Bush (Eds.), Psychosocial Nursing Care (pp. 71-82). Pittsburgh: Oncology Nursing Press, Inc. Vachon, M. (1998). Psychosocial needs of patients and families. Journal of Palliative Care, 14(3), 49-56.

Zabora, J., Brintzenhofeszoc, K., Curbow, B., Hooker, C., \& Piantadosi, S. (2001). The prevalence of psychological distress by cancer site. Psycho-oncology, 10(1), 19-28. 